\title{
Aprendendo as Leis de Newton com os carrinhos de rolimã
}

\author{
Juliano T. da Silva ${ }^{1,2}$, Léa da Cruz Fagundes ${ }^{2}$, Vitor Malaggi ${ }^{1}$, Gildomar Borges \\ Severo ${ }^{1}$, Victor Billy da Silva ${ }^{1}$ \\ ${ }^{1}$ Instituto de Ciências Exatas e Geociências, Curso de Ciência da Computação \\ Universidade de Passo Fundo (UPF) - Passo Fundo - RS - Brasil \\ ${ }^{2}$ Programa de Pós-graduação em Informática da Educação (PPGIE) \\ Universidade Federal do Rio Grande do Sul (UFRGS) - Porto Alegre - RS - Brasil \\ tonezer@upf.br, leafagun@ufrgs.br, malaggi@gmail.com, \{60255, 89167\}@inf.upf.br
}

Resumo. Apresenta-se a experiência de autoria de um objeto de aprendizagem produzido a partir de uma metodologia que possibilita a participação dos envolvidos no processo de aprendizagem (aluno e professor). Esta metodologia consiste na produção de objetos de aprendizagem por equipe multidisciplinar, alunos $e$ professores, iniciada a partir de projetos de aprendizagem.

Palavras-chaves: objetos de aprendizagem, projetos de aprendizagem, leis de Newton

\section{Learning the Newton's laws with the toy cart}

\begin{abstract}
This article presented an experience of authorship of a Learning Object (LO) produced from a methodology that makes possible the participation of the involved ones in the learning process (pupil and teacher). This methodology consists in a production of Learning Object for a multidiscipline team, pupils and teachers, initiate from learning projects.
\end{abstract}

Key-words: Learning Object, projects of learning, Newton's laws.

\section{Introdução}

A escola pública, parte integrante da Sociedade do Conhecimento e da Informação, vem sendo "desequilibrada" pelas Novas Tecnologias de Informação e Comunicação (NTIC's) - seja pela inserção ou ausência destas. Com isso, tornam-se problemas de proporções semelhantes: a falta de acesso as NTIC's bem como ter o acesso e não ser capaz de apropriar-se plenamente destas. Isto invoca a refletir, entre outras questões, que somente o ter acesso as NTIC's não é suficiente para que haja um sistema educacional de qualidade. Assim, novas metodologias de aprendizagem, apoiadas pelas NTIC's devem ser adotadas em conjunto com esta inserção para que possam atender, às necessidades e aos anseios dessa nova sociedade contemporânea.

Neste sentido este artigo busca discutir sobre a aplicação dos Projetos de Aprendizagem, a Informática na Educação e os Objetos de Aprendizagem como uma

\footnotetext{
"Objeto de Aprendizagem premiado na $2^{\mathrm{a}}$ edição do Prêmio "Produção de Objetos de Aprendizagem" do programa Rede Interativa Virtual de Educação (RIVED), promovido pela Secretaria de Educação a Distância (SEED) do Ministério de Educação (MEC) em parceria com o Programa das Nações Unidas para o Desenvolvimento (PNUD). 
metodologia de aprendizagem apropriada, que possibilita a participação dos envolvidos no processo de aprendizagem, em especial, os alunos e professores.

Inicialmente propõe uma versão provisória desta metodologia de aprendizagem que foi aplicada no desenvolvimento de um objeto de aprendizagem. Proposta decorrente das atividades de pesquisa do doutorado (em andamento) no Programa de PósGraduação em Informática na Educação da Universidade Federal do Rio Grande do Sul (PPGIE/UFRGS), a qual estuda a aplicação da metodologia de Projetos de Aprendizagem, com a Informática na Educação e os Objetos de Aprendizagem ${ }^{1}$. Esta também foi parte integrante do projeto de pesquisa da Universidade de Passo Fundo (UPF) "Objetos de Aprendizagem - processo de produção de Material Educacional Multimídia pelos próprios alunos e equipe multidisciplinar".

\section{Metodologia de aprendizagem - versão provisória}

Esta metodologia de aprendizagem é uma intersecção da área de projetos de aprendizagem com os objetos de aprendizagem e apoiada nas NTIC's. Ela está descrita como provisória em virtude das etapas descritas nesta seção terem sido os parâmetros metodológicos iniciais da pesquisa, os quais foram definidos antes da produção do Objeto de aprendizagem "Aprendendo as Leis de Newton com os Carrinhos de Rolimã".

O ponto de partida para a produção dos objetos de aprendizagem é a criação de uma equipe multidisciplinar para produção de objetos de aprendizagem. A proposta inicial foi que participassem os seguintes integrantes: pesquisador; professores das disciplinas (inicialmente em disciplinas da área de ciência e matemática); alunos; Coordenação pedagógica; Multiplicadores NTE (Núcleo de Tecnologia Educacional); Bolsista(s) de Iniciação Científica; Especialista(s) da área de ciência e matemática. A equipes teriam reuniões semanais, para estudo e apropriação das tecnologias pelos participantes, estudo, projeto e desenvolvimento de objetos de aprendizagem.

A interação entre os integrantes da equipe de produção, resumidamente funcionaria assim: os especialistas (assumindo uma função de consultor) forneceriam o suporte científico em ciência e matemática para os professores da escola e para a equipe técnica. Os professores da escola, por sua vez, proporcionariam auxílio aos alunos em seus projetos de aprendizagem. Os alunos, através de seus projetos de aprendizagem, seriam os autores principais do roteiro do objeto de aprendizagem. A partir deste roteiro, o objetivo é que todos os integrantes da equipe participassem da produção do OA. A produção dos objetos de aprendizagem foi divida nas seguintes etapas:

Etapa 1: Formação de grupos de alunos do ensino médio de escola pública, de acordo com os projetos de aprendizagem.

Etapa 2: Definição dos Projetos de Aprendizagem pelos alunos. Estes são os responsáveis pela escolha do que gostariam de aprender.

Etapa 3: Desenvolvimento dos Projetos de Aprendizagem: (a) certezas provisórias; (b) dúvidas temporárias; (c) pesquisa em internet, bibliotecas, livros, revistas e outras fontes de pesquisa; (d) organização do material pesquisado; (e) produção de site para o projeto de aprendizagem.

\footnotetext{
${ }^{1}$ Juliano Tonezer da Silva, sob orientação da $\operatorname{Prof}^{\underline{a}} \operatorname{Dr}^{\mathrm{a}}$ Léa da Cruz Fagundes. 
Etapa 4: Produção dos objetos de aprendizagem, levantamento das áreas temáticas e conceitos a serem abordados. (a) planejamento: concepção inicial do objeto de aprendizagem a partir dos projetos de aprendizagem; (b) projeto do OA na forma de roteiros de tela; (c) Design Pedagógico: descreve os objetivos educacionais, tema central e estratégias de aprendizagem; (d) Desenvolvimento do OA; (e) Elaboração do Guia do Professor: deverá atuar como um manual simples, com sugestões de aplicação e utilização pelo agente pedagógico (aluno ou professor). Este guia aborda aspectos como: objetivos, conceitos, questões para discussão, atividades complementares, sugestões de leitura.

Por fim é importante ressaltar que esta foi a proposta provisória da metodologia de aprendizagem e que a mesma, após a experiência da produção do objeto de aprendizagem Carrinho de Rolimã, deverá sofreu modificações.

\section{Projetos de Aprendizagem}

Inicialmente, ao introduzir esta questão de diferenciação e de busca de semelhanças nas diversas acepções conferidas ao ato de projetar na educação, deve-se frisar que o objetivo maior é o de levantar questionamentos sobre este assunto, e não o de fornecer uma resposta pronta ou correta a este debate. No entanto, serão apontadas acepções encontradas de "pedagogia de projetos", "projetos de trabalho" e "projetos de aprendizagem (aprendizagem por projetos)".

Para Hernández (2002, p.1), as diferenças fundamentais entre os projetos de trabalhos e a pedagogia de projetos são:

(...) em primeiro lugar, o contexto histórico. A pedagogia de projetos surge nos anos 1920 e projetos de trabalho surge nos anos 1980. Além disso, os princípios são diferentes. A pedagogia de projetos trabalhava um modelo fordista, que preparava as crianças apenas para o trabalho em uma fábrica, sem incorporar aspectos da realidade cotidiana dentro da escola. Os projetos de trabalho tentam uma aproximação da escola com o aluno e se vinculam muito à pesquisa sobre algo emergente.

Afora o contexto histórico, o que mais chama a atenção na afirmação de Hernández (2002) é a vinculação da pedagogia dos projetos com o conceito fordista de produção industrial. Neste contexto o autor pontua que na pedagogia dos projetos, a qual seria influenciada pelo fordismo, os aspectos da vida cotidiana não são integrados ao contexto escolar, pois ações como estas não estariam de acordo com os princípios e necessidades da ideologia de produção fordista. Esta afirmação pode-se dizer que é no mínimo polêmica, pois, um dos objetivos da pedagogia de projetos é justamente tentar trazer para dentro da escola a vida, a realidade da comunidade e do aluno, idéia esta defendida principalmente por Dewey e Kilpatrick, os precursores do método dos projetos.

Outro ponto que gera controvérsias entre a pedagogia de projetos e os projetos de trabalho é a questão de tratar o ato de projetar como um método ou não. Kilpatrick, que foi o discípulo direto de Dewey, sistematizou as idéias abordadas por Dewey em suas obras em forma de método, quando levou para a sala de aula, ou seja, para a prática, as contribuições do seu mestre. Assim, Kilpatrick chamou de método de projetos a prática de usar os projetos na escola, para transformar esta em um espaço aberto ao real. Já 
Hernández (1998, p.75), veementemente explicita que “(...) os projetos de trabalho devem deixar de ser considerados como um método". Para este autor, ao considerar os projetos de trabalho como um método, está sendo produzida uma complexidade de tal ordem sobre o conhecer no ato de projetar que, a menos que se queira caminhar numa direção de redução e simplificação das propostas de projetos, conseqüentemente ter-se-á uma desfiguração dos projetos de trabalho.

Retornando um pouco ao contexto histórico, ainda deve-se pontuar um grande acontecimento que marcou a prática dos projetos nos anos 80: a revolução cognitiva, desencadeada pelos estudos de Jean Piaget (1896 - 1980). Esta "revolução", que marcou a maneira como se pensava a aprendizagem e a aquisição dos conhecimentos, e que, consequientemente, gerou reflexos na área educacional, fez com que, na ótica de Hernández (1998 p.71), acontecesse um novo fluxo de interesse sobre os projetos, seguido da realização de pesquisas para interpretar o ato de projetar às luzes destas novas idéias.

Tem-se ainda o uso do termo "Projetos de Aprendizagem" ("Aprendizagem por projetos") descrito e utilizado por Fagundes (2000). Teoricamente, o ato de projetar na concepção desta autora assemelha-se em alguns pontos aos projetos de trabalho de Hernández, bem como também faz referência, conseqüentemente, a elementos da Pedagogia dos Projetos. A questão do uso do termo "aprendizagem" deve-se ao fato de que a autora em questão apóia-se de maneira intensa na teoria construtivista, para a formulação dos seus conceitos sobre o ato de projetar. Assim, o uso da acepção "Aprendizagem por projetos" deve-se ao fato de que, para Fagundes (2000), o objetivo maior a ser perseguido é a aprendizagem dos conceitos, construídos através do ato de projetar. Explica-se assim o uso do termo "aprendizagem" juntamente com "projetos", diferenciando-se das outras acepções vistas anteriormente.

Outro ponto fundamental, além dos conceitos de cada um destes termos, é como os projetos podem ser aplicados em sala de aula. É unânime a idéia entre os diversos autores de que um projeto deve-se iniciar pela escolha de um tema de pesquisa. Neste contexto, verifica-se uma questão importante: o tema em si não precisa ser um assunto, mas pode também ser um problema para o qual se busca uma solução. Ressalta-se uma característica importantíssima: esta escolha deve ser exclusiva do aprendiz em questão, ou do grupo de aprendizes. Esta posição apóia-se nas idéias construtivistas desenvolvidas por Jean Piaget (PIAGET, 1990).

Após ser definido o tema/problema de pesquisa do projeto, alguns autores como Fagundes (2000), Martins (2001) e Hernández \& Ventura (1998), sugerem de maneiras semelhantes o levantamento ou diagnóstico dos saberes prévios do aprendiz. Em particular, vale ressaltar a posição de Fagundes (2000), que vincula os saberes prévios dos aprendizes a um processo de definição das certezas provisórias e dúvidas temporárias. Estas certezas correspondem o que naquele determinado momento da aprendizagem os alunos tomam como verdade sobre um assunto. As dúvidas são o que ele gostaria de aprender a mais sobre o assunto. Nada impede, e com certeza irá ocorrer, que no percurso dos projetos "muitas dúvidas tornam-se certezas e certezas transformam-se em dúvidas; ou, ainda, geram outras dúvidas e certezas que, por sua vez, também são temporárias, provisórias". (FAGUNDES, 2000, p.17) 
Definido o tema/problema, e as certezas e dúvidas temporárias dos alunos sobre este, parte-se para a execução do projeto. Nesta etapa, os alunos irão pesquisar, buscando informações que possam comprovar ou desmentir suas hipóteses, ou poderão também expandir um conhecimento já adquirido, que estava incompleto. Vale ressaltar que não é objetivo de um projeto de aprendizagem fazer com que o aluno meramente copie informações, o que não mudaria em nada o caráter transmissivo antes praticado em sala de aula. Assim, os alunos vão adquirindo competência e autonomia para selecionar o que é importante, e descartar o que é supérfluo. Estas informações podem ser retiradas de diferentes fontes, tais como: revistas, jornais, CD-ROM's, Objetos de Aprendizagem, internet, etc.

O que caracteriza bem esta fase é a ação do aluno, o qual romperá com a passividade tradicional imposta a si na sala de aula, para tornar-se agente de sua própria aprendizagem. Ao professor, cabe observar, orientar, questionar os procedimentos e métodos utilizados, levantar dúvidas que façam os alunos refletirem sobre o problema de pesquisa, organizar os ambientes de aprendizagem, servindo também ele próprio de especialista em sua área, se assim for necessário.

À medida que vão sendo descobertas novas informações, os alunos devem ser orientados a construir o conhecimento. Assim, eles realizarão uma análise comparativa das suas hipóteses antes estabelecidas, com as informações que conseguiram encontrar na pesquisa realizada, para verificar que se algumas coisas que antes afirmavam ser corretas não condizem ou condizem com a realidade, ou que estão incompletas, com falta de algumas informações adicionais ou não. Assim, ocorrem os "conflitos cognitivos", a partir de onde o conhecimento começa a ser expandido, aumentado, bem como será mais desenvolvida a capacidade de pesquisa e problematização de temas pelos alunos.

As últimas ações necessárias à conclusão de um projeto são a apresentação e a avaliação dos resultados. $\mathrm{Na}$ apresentação os alunos poderão expor seus projetos, identificando e relatando a turma suas descobertas, hipóteses criadas e conclusões. Este momento é muito especial, pois além de divulgar o trabalho dos alunos ao grupo, ajuda na criação de um ambiente de aprendizagem cooperativo, bem como desenvolve nos alunos a capacidade de expressão de suas idéias e a prática de trabalho e convivência em grupo. A apresentação pode ser feita de diversas maneiras (teatral, musical, grupo de debates, seminários, etc.), não existe um meio correto ou perfeito a ser seguido.

Na última fase do projeto se procede a avaliação, que tem por objetivo verificar se os alunos conseguiram construir os conhecimentos que foram estudados durante $\mathrm{o}$ desenvolvimento do projeto. Assim, para Hernandez (1998, p.96), através do processo avaliativo pretende-se que "(...) os estudantes possam aplicar (transferir) os conhecimentos que aprenderam para situações reais e de simulação, e não apenas responder a enunciados verbais, visuais ou numéricos de caráter reprodutivo". Como se pode perceber através desta afirmação, o modelo de avaliação adotado por Projetos de Aprendizagem distancia-se significativamente do método de avaliação tradicional, pois não visa medir, através de provas ou trabalhos de caráter meramente quantitativos, um contexto ou desempenho isolado do processo de aprendizagem.

Pelo contrário, o objetivo da avaliação através dos projetos é observar, interpretar, entender e então avaliar o processo como um todo. Isso implica em verificar como o 
aluno desenvolveu o entendimento de um determinado conceito, se já consegue refletir ou manipular situações aonde necessitem da aplicação dos conceitos aprendidos, que recursos conseguem utilizar para construírem um determinado conhecimento, entre outros.

\section{Objetos de Aprendizagem}

Os Objetos de Aprendizagem, na área de Informática na Educação, estão sendo apontados como uma das principais "tendências" tecnológicas educacionais, pois possibilitam através de suas características conferirem ao processo de aprendizagem um caráter interativo, dinâmico e motivador.

Por ser uma área de domínio técnico e científico nova, e que vem sendo estudada e pesquisada há relativamente pouco tempo, se comparada a outras áreas da Computação e da Informática na Educação (a primeira utilização do termo "Objeto de Aprendizagem" credita-se a Wayne Hodgins, no ano de 1994), diversas são as definições ou concepções sobre o que vem a ser um OA. Assim, diversos autores, pesquisadores, consórcios e instituições vêm "cunhando" seus próprios conceitos, não existindo ainda um consenso sobre uma conceituação teórica, bem como uma nomenclatura aceita por todos. Neste artigo em específico, será relatada e adotada a acepção de David Wiley, um dos autores mais citados em artigos e trabalhos científicos desta área. Segundo Wiley (2000) (tradução nossa), um OA seria “(...) qualquer recurso digital que pode ser reusado para suportar a aprendizagem". Ainda nesta linha de pensamento, este autor continua em sua definição postulando que esta tecnologia educacional "(...) inclui tudo que pode ser distribuído pela rede sob demanda, seja isto grande ou pequeno". Para este autor, recursos digitais pequenos podem ser fotos, vídeos ao vivo ou gravados, animações, etc. Como recursos digitais grandes podem ser citados os exemplos das páginas Web, as quais combinam diversos elementos de mídias menores, como textos, imagens, sons, etc. Os OA's possuem ainda diversos tópicos que dissertam sobre variados assuntos e conceitos do seu contexto, tais como as suas características, metáforas e metodologias de desenvolvimento. Estes tópicos ajudam a entender melhor a definição/concepção dos OA's, bem como os métodos de desenvolvimento voltados especificamente para esta tecnologia educacional. Com relação as características dos OA's, pode-se citar principalmente quatro destas: reutilização, combinação ou agrupabilidade, identificação por metadados e interatividade.

No campo das metáforas, que visam explicar as definições e características dos OA's às pessoas iniciantes na área de maneira simples, acurada e de fácil entendimento e assimilação, destacam-se principalmente três: a) a metáfora LEGO ${ }^{\circledR}$, que faz uma analogia entre os OA's e as peças do brinquedo LEGO ${ }^{\circledR}$, postulando que assim como as peças deste brinquedo, os OA's são pequenos blocos de informação os quais podem ser combinados e reutilizados em diversos contextos; b) a metáfora do átomo, proposta por Wiley (2000), que vislumbra os átomos como sendo a melhor analogia aos OA's. Segundo este autor, estas partículas mínimas que formam tudo o que existe também podem se combinar e re-combinar, bem como podem ser utilizadas em diversos "contextos", mas somente em algumas condições e casos, e não de maneira indiscriminada, como pressupõem a metáfora $\mathrm{LEGO}^{\circledR}$; c) a metáfora da construção, proposta por MASIE (2003), que se baseia fortemente na característica atual dos materiais de construção de serem pré-fabricados, ou pré-moldados, para fazer uma 
analogia com os OA 's e explicar suas principais características. Assim, da mesma maneira que os materiais pré-moldados, os OA's também podem ser reutilizados em diversos contextos, através da (re) combinação e de sua característica modular, possuem diversos tamanhos (granularidade), etc.

Concluindo, cita-se as metodologias de desenvolvimento voltadas especificamente para a produção de Objetos de Aprendizagem: a) a metodologia RIVED (Rede Internacional Virtual de Educação), a qual possui seis fases distintas de desenvolvimento, tendo por objetivo produzir módulos que contenham uma ou mais atividades em forma de OA's para o auxílio ao processo de aprendizagem de determinadas áreas do conhecimento envolvidas no currículo do ensino médio; b) a metodologia da Wisconsin On-line Resource Center, que consiste em uma série de quatro fases, sendo que cada uma destas possuem diversos passos, ou itens a serem verificados e/ou executados; c) a metodologia mista proposta por Scariot (2005), que tem como diferencial a combinação de elementos dos métodos ágeis, e em especial do XP (Extreme Programming), com uma metodologia já desenvolvida para a produção específica de OA's, o método RIVED.

\section{Desenvolvimento do Objeto de Aprendizagem "Aprendendo as Leis de Newton com os carrinhos de rolimä"}

Alguns fatores teóricos, técnicos e conceituais são de suma importância para a compreensão do processo de autoria do OA Carrinho de Rolimã. Um primeiro fator é que o OA em questão teve seu desenvolvimento iniciado a partir de um projeto de aprendizagem proposto por um grupo de alunos do ensino médio de uma Escola pública participante da pesquisa de doutorado citada na introdução.

Procurou-se seguir as etapas definidas na metodologia de aprendizagem descrita na seção 2. Algumas etapas puderam ser adotadas e outras parcialmente, em virtude de fatores externos e do desenrolar da pesquisa. No transcorrer desta seção são apresentados os aspectos mais relevantes da produção do OA.

As etapas 1, 2 e 3 puderam ser concretizadas como haviam sido definidas inicialmente, com algumas ressalvas para a etapa 3 . Já na etapa 4, produção do objeto de aprendizagem, é que aconteceram situações interessantes para a análise.

Um dos primeiros acontecimentos foi a paralisação do magistério estadual no início do ano de 2006. A escola participante do projeto de pesquisa aderiu a greve e infelizmente, a produção do objeto de aprendizagem teria que aguardar o retorno das atividades. É importante destacar que as etapas 1, 2 e 3 haviam sido desenvolvidas no ano anterior, em 2005. Enquanto a paralisação acontecia optou pelo andamento da pesquisa e desenvolvimento do objeto de aprendizagem pela equipe composta pelo pesquisador e os bolsistas de iniciação científica.

A divisão das funções dentro da equipe foi através das afinidades e gostos individuais de cada integrante. Deste modo, ficou definido que: uma pessoa ficaria responsável pela parte de design e desenho gráfico; outro integrante da equipe seria responsável pelas partes que envolviam animações de qualquer natureza; e por último, um integrante ficaria responsável pela programação em ActionScript das diversas funções necessárias ao OA. 
Outro aspecto de grande relevância foi relacionado aos conceitos abordados pelo objeto, ou seja, as leis dos movimentos ou leis de Newton. Neste momento deparou-se com uma realidade que vem sendo desvelada em avaliações nacionais e internacionais do sistema educacional brasileiro: alunos estão concluindo o ensino médio sem aprender fundamentos e conceitos de ciência e matemática. Para entender melhor esta constatação se faz necessário descrever a visão geral do OA carrinho de rolimã, que é a simulação da brincadeira popular - corridas de carrinho de rolimã - que fez/faz parte do cotidiano infanto-juvenil. Neste OA o aluno é incentivado a se imaginar na garagem de sua residência ou de amigos com o objetivo de "configurar" a melhor possibilidade de carrinho de rolimã, considerando conceitos como: as leis de Newton $\left(1^{\mathrm{a}}, 2^{\mathrm{a}}\right.$ e $\left.3^{\mathrm{a}}\right)$, massa, peso, gravidade, atrito, força, aceleração. Nesta brincadeira são colocados dois carrinhos de rolimã, um ao lado do outro, para calcular qual deles chegará primeiro ao final da pista. Para isto, o aluno deverá compreender os conceitos das leis dos movimentos para poder informar corretamente as variáveis solicitadas.

Assim, surgiu a problemática: como se aplicam as leis de Newton no objeto de aprendizagem carrinho de rolimã? Este problema foi decorrente da falta de domínio dos conceitos da parte do pesquisador e bolsistas de iniciação científica. Na metodologia proposta, este tipo de situação "seria" resolvida com a participação do(s) professor(es) da área (neste caso, professor(es) de física) que disporia da assessoria do especialista. Seria, pois aqui, retoma-se o segundo aspecto relevante: que o professor também precisa "reaprender". Isto foi constatado após várias reuniões com professores estaduais que lecionam ou lecionaram a disciplina de Física no Ensino Médio, onde era apresentado o projeto do objeto de aprendizagem e explicitado o que se buscava. Abaixo a transcrição de dois destes diálogos:

- Um dos programadores da equipe perguntou a um professor ${ }^{2}$ - que ministra a disciplina de física - sobre um determinado "ponto da teoria das leis de Newton". O professor olhou no livro, olhou de novo, não conseguiu achar o assunto e respondeu: "cara, esta parte da teoria eu ainda não decorei pra passar pros alunos, mas se você quiser eu indico pra você uma professora que dá aula a muito tempo e já sabe toda a matéria de cor". (diálogo 1).

- A outra afirmação do professor foi de que não era possível fazer as ligações entre as leis de Newton... Nas palavras do professor "(...) eu sei os conteúdos em separado, primeiro eu ensino um deles, depois passo pro outro, e assim por diante... tem conteúdos que serão dados que nem eu estudei ainda pra passar pros alunos". (diálogo 2).

Enfim, para o avanço da pesquisa e produção do objeto de aprendizagem se fez necessário então que os bolsistas de iniciação científica se lançassem à pesquisa para aprender os conceitos abordados pelo OA. Desta forma, o desenvolvimento da programação e animação do objeto em si teve a duração de aproximadamente 6 meses, porém com outras tarefas realizadas simultaneamente a este processo. Dentro da metodologia adotada, o grupo de pesquisa teve reuniões semanais durante todo este período, sendo elas realizadas nas terças-feiras, no campus da UPF da cidade de Soledade-RS, onde ocorria também a produção do OA. Com freqüência, os integrantes

\footnotetext{
${ }^{2} \mathrm{O}$ referido professor portava um livro de física em suas mãos
} 
da equipe de desenvolvimento reuniam-se em horários alternativos, seja na forma presencial ou através das NTIC's.

Como fruto desta pesquisa foi produzido o objeto de aprendizagem "Aprendendo as Leis de Newton com os Carrinhos de Rolimã". Este OA, classificado como Animação e simulação, se destina ao ensino médio, e objetiva auxiliar no processo de aprendizagem dos conceitos de física relacionados às Leis de Newton. A idéia geral é proporcionar aos alunos um ambiente virtual e interativo que os motive a compreensão dos conceitos abordados pelo OA através da verificação e aplicação destes em uma realidade simulada. A figura 1 apresenta a tela "configuração", onde o aluno precisa informar 5 parâmetros de seu carrinho de rolimã: (1) Massa do chassis; (2) Tipo de roda (borracha ou metal); (3) Massa do desafiante; (4) Tipo de pista (asfalto ou terra); (5) Força do empurrão. Estes parâmetros são necessários para que seja possível a simulação de uma corrida de carrinho de rolimã, entre o desafiante (aluno) e o computador (são gerados randomicamente). Após a configuração dos parâmetros do competidor, o aluno pode iniciar a simulação da corrida. O "vencedor" será o carrinho de rolimã que estiver "melhor" configurado, conforme os conceitos abordados pelo OA. Ainda é possível, através da tela de resultados, visualizar os resultados obtidos e analisá-los, refletindo e relacionando os conceitos das leis do Movimento.

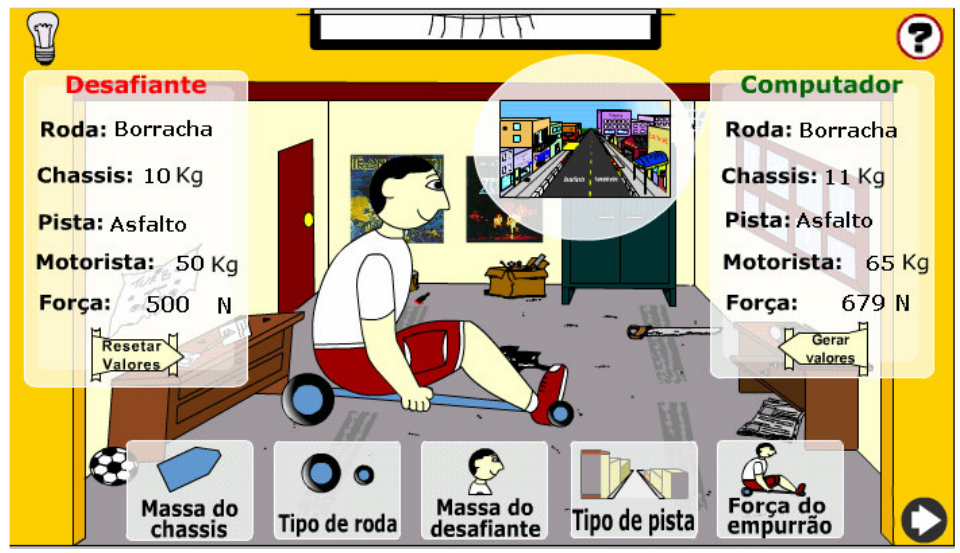

Figura 1. Tela de configuração

Destaca-se que o papel do professor torna-se cada vez mais importante, pois este deverá orientar os alunos durante esta atividade e auxiliar na compreensão dos conceitos relacionados. Pois, é importante que o aluno entenda os conceitos envolvidos para que seja possível configurar o seu carrinho de rolimã, evitando que o objeto de aprendizagem seja utilizado de uma forma simplória, como na tentativa e erro.

Para finalizar, este objeto de aprendizagem não tem a intenção de provocar competição entre os alunos e nem entre o aluno e o computador. Ele busca, através de uma forma lúdica, construtivista e de uma brincadeira infanto-juvenil (corridas de carrinho de rolimã) relacionar os conceitos das Leis de Newton com o dia-a-dia do aprendiz.

\section{Considerações Provisórias}

Através da experiência de autoria de um objeto de aprendizagem pode-se verificar que é possível avançar na definição de uma metodologia para a produção de objetos de aprendizagem que possibilite a participação dos envolvidos no processo de aprendizagem (alunos e professores), com o objeto de melhorar a aprendizagem destes 
nas áreas de ciência e matemática no ensino médio. E que a concepção dos objetos de aprendizagem a partir de projetos de aprendizagem se torna uma possibilidade indispensável.

Porém tem que se avançar e buscar alternativas de aprendizagem para a Escola Pública atual, onde predomina entre outros aspectos, a transmissão (reprodução) de conhecimentos, a fragmentação, todos aprendendo o mesmo conteúdo ao mesmo tempo.

Assim, precisamos refletir a partir de situações, como a do diálogo 1 (seção 5), onde aparece o ranço "condutista" deste professor, que se considera um indivíduo sem capacidade de construção, e sim de imitação (decorar), pretendendo passar (leia-se transmitir) isso para os alunos. Já no diálogo 2 mostra-se o caráter de fragmentação do conhecimento em disciplinas isoladas e a separação dos próprios conteúdos de uma mesma disciplina dentro dela mesma.

Também deve se ressaltar que o professor não é o único responsável por estas situações. Pois em sua formação é possível que ele tenha aprendido que na prática pedagógica, a aprendizagem dos alunos se dá por imitação e reforço seletivo, onde se imita várias vezes até a resposta estar de acordo com o esperado. É possível que tenha aprendido que o conhecimento se transfere, e que o sujeito não é ser ativo na sua aprendizagem. E que o currículo deve ser dividido em disciplinas, as disciplinas em conteúdos, sem necessidade de compreensão global das suas interligações.

\section{Referências Bibliográficas}

FAGUNDES, Léa da Cruz. et al. (2000) Aprendizes do futuro: as inovações começaram. Coleção Informática para a mudança na Educação.

MEC/SEED/ProInfo, 2000.

HERNÁNDEZ, Fernando. (2002) Pesquisar para aprender. Disponível em: $<$ http://novaescola.abril.com.br/ed/154_ago02/html/hernandez.doc>.

HERNÁNDEZ, Fernando. Transgressão e mudança na educação: Os

Projetos de Trabalho. Porto Alegre: Artmed, 1998.

HERNÁNDEZ, Fernando; VENTURA, Montserrat. A organização do currículo por projetos de trabalho: $O$ conhecimento é um caleidoscópio. 5 . ed. Porto Alegre: Artmed, 1998.

PIAGET, Jean. Epistemologia Genética. Tradução Álvaro Cabral. São Paulo: Martins Fontes, 1990 (Universidade Hoje).

MARTINS, Jorge Santos. O trabalho com projetos: Do ensino fundamental ao ensino médio. 3. ed. São Paulo: Papirus, 2003.

MASIE CENTER LEARNING AND TECHNOLOGY E-LAB \& THINKTANK. (2003) Making Sense of Learning Specifications \& Standards: A Decision Maker's Guide to their Adoption. (2003).

SCARIOT, Emanuel Fernando Machado. (2005) Proposta de uma metodologia mista para o desenvolvimento de Objetos de Aprendizagem. Monografia (Bacharelado em Ciência da Computação) - Universidade de Passo Fundo, Passo Fundo, 2005.

WILEY, David A. (2000) Connecting learning objects to instructional design theory: A definition, a metaphor, and a taxonomy In: WILEY, David A. (Org.), The Instructional Use of Learning Objects: Online Version. (2000). 